\title{
Neonatal tooth in a preterm infant
}

\author{
Mehmet Nevzat Cizmeci • Mehmet Kenan Kanburoglu • \\ Fatma Karadag Uzun • Mustafa Mansur Tatli
}

Received: 16 November 2012 / Accepted: 4 December 2012 / Published online: 30 December 2012

(C) Springer-Verlag Berlin Heidelberg 2012

\begin{abstract}
A neonatal tooth is defined as a tooth, which erupts within the first month of life. Herein, we report a premature infant with a neonatal tooth.
\end{abstract}

Keywords Neonatal teeth $\cdot$ Preterm infant

A 1,520-g male infant was born at 31-week gestation to a 28-year-old gravida 2 para 1 mother who received regular prenatal care. On day 20, a protuberance has occured on the medial part of the mandibular gingiva and 1 week later a neonatal tooth has erupted at the region of the left lower central incisor (Fig. 1). The infant exhibited significant discomfort and difficulty in bottle feeding during eruption, and the tooth was extracted on the 40th postnatal day due to its hypermobility.

A "natal tooth" is a distinctly rare condition defined as a tooth present at birth, and a neonatal tooth is which erupts within the first month of life [2]. The most common site of eruption is the lower central incisor area. The etiology of these teeth is still unknown, and careful evaluation of infants with natal or neonatal teeth is mandatory for possible syndromic conditions [1]. Eruption of a natal/neonatal tooth is a subject of interest for both pediatricians and dentists. There is only one report of a natal tooth in the literature of an extreme premature infant [3]; however, to our knowledge, this is the first reported case of a neonatal tooth in a preterm infant.

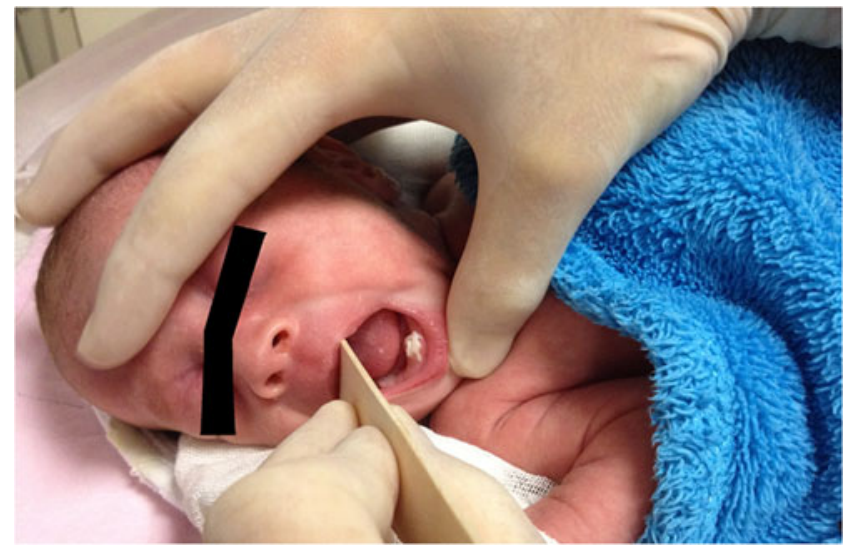

Fig. 1 Erupted neonatal tooth at the region of the left lower central incisor

\section{References}

1. Basavanthappa NN, Kagathur U, Basavanthappa RN, Suryaprakash ST (2011) Natal and neonatal teeth: A retrospective study of 15 cases. Eur J Dent 5:168-72

2. Massler M, Savara BS (1950) Natal and neonatal teeth; a review of 24 cases reported in the literature. J Pediatr 36:349-59

3. Sureshkumar R, McAulay AH (2002) Natal and neonatal teeth. Arch Dis Child Fetal Neonatal Ed 87:227 